\title{
Ways and Methods for the Cultivation of Students' Practical Ability in Higher Engineering College
}

\author{
Gui-fu Wu, Yua-hua Jia, Bing-bing Yan,Qi-sheng Liu,and Dong-wei Shao \\ Jiamusi University, Jiamusi, Heilongjiang, China
}

\begin{abstract}
With the progress of social economy, the country increases the demands of engineering students on the practical skills in Higher Engineering College. Higher technical schools should develop competency-based talents with the practice and innovation. This article mainly analyzes and studies the status of the students on engineering practice ability in Higher Engineering College, to find the ways and methods of cultivating students' practical ability.
\end{abstract}

Keywords: Engineering students; practical ability; way

\section{普通高等工科学校学生实践能力的培养途径及方法}

吴贵福 贾元华 颜兵兵 刘启生 邵东伟

佳木斯大学, 佳木斯, 黑龙江, 中国

摘 要 随着社会经济的进步, 国家对工科学生实践技能的要求越来越高, 普通高等工科学校应该培养出具有实践与创新能力型 人才。本文主要从普通高等工科学校学生实践能力的现状进行分析与研究, 找到培养学生动手能力的途径及方法。

关键词 工科学生; 实践能力; 途径

现今工科大学生实践能力普遍偏低, 难以适应社会发 展的需要。目前我国必须拥有数量众多的具有创新能力和 实践能力的人才, 才能在风云变幻的世界竞争中立于不败 之地。作为普通高等工科学校的责任就是培养并造就一批 具有竞争性、高素质、高质量的工程技术人才, 工科大学 生实践能力的培养和提高是我国跨世纪经济发展的需要, 也是我国高等工程教育不断改革发展的趋势。

\section{1. 我国工科大学生实践能力的现状}

现代大学教育的根本目标是培养具有创新精神和实 践能力的高素质人才, 随着世界工业科技日新月异的发展, 知识经济的社会已经来临, 高等教育在一个国家发展代表 着一个国家经济的发展, 如何培养工科大学生实践创新能 力是当代教育最大的核心所在。当前我国工科大学生实践 能力普遍较差主要反映在以下两个方面:

\section{1 企业对工科大学生实践能力评价不高}

工科毕业生在校期学习了专业学科理论知识, 但是 不能把所学习专业基础理论与具体工作实际相结合。同 时, 对企业生产模式不熟悉, 甚至熟悉较慢, 再加上不 愿意深入去研究企业生产实际, 又不能虚心地与企业技 术管理干部及工人相勾通, 有的毕业生工作了 2-3 年还 不能独立承担工作任务。基本技能不过硬，如作图软件 应用，技术文件的总结等基本功不扎实，也没有养成用 图形、图表进行交流和表达设计方案、技术思想的习惯, 缺乏吃苦耐劳、不愿意到科研和生产一线去工作等等。

企业希望大学生能增加对社会的了解和实践,端正 就业态度; 了解社会目前的情况, 及时调整就业心态, 丰富自己的实践经验; 提高自身素质，多参加社会实践 并加强社会实践, 增强社会适应能力, 务实勤奋。

黑龙江省教育科学 “十二五” 规划课题 “工科大学生实践能力培养研究” (GBC1212095); 黑龙江省新世纪教育教学改革工程项目 “地 方高校课堂教学有效性的“分析一策略-实施-评价” 过程集成系统研究” (JG2014011044) 


\section{2 工科大学生就业困难}

随着我国高校毕业生就业形势的日益严峻, 大学生就 业越来越成为社会关注的焦点, 开展大学生创新实践教育 是高等教育的迫切要求, 也是破解当前就业难问题的重要 途径。现在的大学毕业生中, 只有能够充分满足并能尽快 适应用人单位需求的人才, 才有竞争的优势。现今:企业 招聘大学毕业生时, 最看重的是毕业生的 “综合能力”, 其次为 “潜力”, 第三为 “品德”。

每年应届毕业生在就业时, 都要参加各种各样的招聘 会, 有的企业走进校园进行专场招聘会, 各高校的学生通 过网络, 了解到招聘信息后, 纷纷到招聘地点去投简历, 甚至有的学生把自己的简历做成象宣传单一样, 给各个企 业发放，但是真正能够收到企业面试信息的没几家企业， 一方面说明学生在不了解企业基本情况下，盲目地去投简 历, 没有做好充分的准备, 不知道自己将来想要做什么, 自己能否胜任企业的工作; 另一方面, 在就业之前, 没有 充分对在校期间所有完成各项学习任务进行归纳总结, 其 中包括：国家对学生外语及计算机等级考核是否合格、在 校期间参加的各项实践活动、国家级或省（校）级各类创 新能力赛等。这两方面原因造成被企业拒之门外。

根据近几年我校热能与动力工程专业学生就业情况 分析如下分析：1）格力空调公司首先要通过招聘网页中 能力测试题，这些题目中基本上是理论与实践相结合的题 目, 学生要通过测试后才能进入面试, 我校今年有 5 名同 学在网上答题, 其中有 3 人不过关, 没有得到面试机会; 2 ) 长城汽车公司在笔试中, 出一些行测题目, 目的是要考核 学生的综合能力, 通过笔试后才能进入面试。我校近三年 热能与动力工程专业学生共有 25 人签约长城汽车公司, 这 些学生都是通过该公司层层面试选拔出来, 通过对这些学 生走访, 我们也了解到现今企业需要什么人材, 为我们下 一步重新制定培养方案提供了理论基础。还有些企业在招 聘学生时出一些工程实践的题目, 目的是考核学生的动手 能力。但是大部分学生在校期间成绩相当好, 但在公司笔 试及工程实践能力测试中不能通过，说明当前我国工科大 学生的实践及综合能力普遍偏低的现实, 造成这种现状的 原因是多方面的。

\section{2. 工科大学生实践能力培养的方案的确定}

我国现今工科大学生知识结构如图 1 所示, 各工科院 校都对培养方案进行了相关修订，但也存在着一些不足， 课程设置不能与具体实践相结合，专业工程实践比较少， 造成学生在就业后不能很快地适应所签工作需要, 这主要 是在培养目标出现了偏差所造成的。

由于人们大多狭义地理解实践能力就是动手能力、操
作能力, 所以一些工科教师认为学生的实践能力应该通 过实践教学活动来培养, 而忽视了课堂教学活动也是培 养学生实践能力的重要环节。所以要制定好培养方案, 是所有工科院校摆在面前的主要问题, 我校针对国家教 育部专业骨干课程调整文件, 对毕业生进行走访, 与有 关用人单位进行勾通, 对能源与动力工程专业培养方案 进行修订, 培养方案主要加强了学生的动手能力的培 养, 增加了实践环节的周次, 在选修课中注重了本专业 现今企业的需求而设。

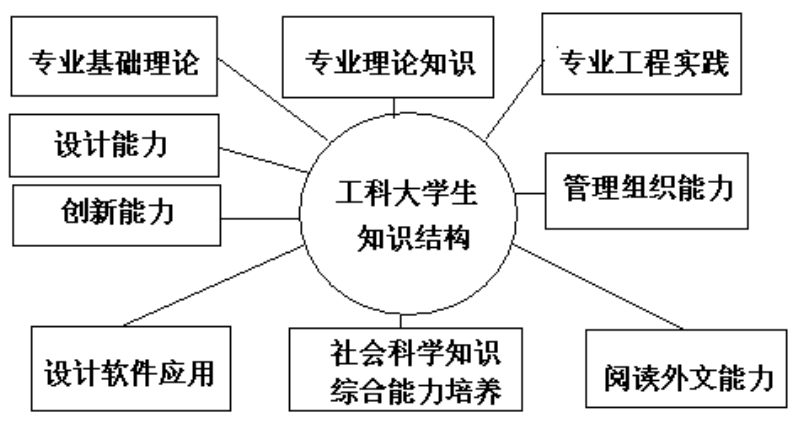

图 1 工科大学生知识结构

通过对我校热能与动力工程专业培养方案的重新 修定，使毕业生掌握工程热物理、机械学和电子控制技 术的综合理论知识和实践技能, 具有从事能源与动力工 程领域的科学研究、设计开发、制造、运行和管理的基 本能力, 有良好的适应性和继续深造基础。符合教育部 对本科教学的基本要求, 同时, 能够更好地适应企业的 需要, 避免学生到企业中不能够适应企业的工作, 为国 家培养出创新实践能力的人才。

工科大学生毕业后主要工作在工业生产第一线, 从 事设计、制造、运行、研究和管理等工作。因此, 高等 工程教育直接作用与社会外部环境 (政治、经济、文化、 科技、生态等等), 双方互动性很大，工科大学生的培 养必须优先考虑外部需求。高校、大学生、用人单位之 间不勾通，导致了人力资源不能合理、有效配置，对整 个社会来说会造成巨大的人力浪费, 对三方都会造成不 同程度的损失。近年来, 为缓解大学生就业压力, 国家 接连出台了多项就业促进政策。高校是提升大学生就业 能力的主阵地, 也纷纷通过各种手段, 增强毕业生的就 业能力, 提高就业率, 而要真止提高大学生的就业能力, 必须提高工科大学生创新实践能力。

对我国工科大学生现状进行分析与研究, 制定适应 社会发展需要的合格人才, 是目前高校在培养规律中必 须考虑的问题, 创新及动手能力的培养, 不是四年本科 
大学能够做到完善的, 这需要学生有扎实的基本理论知识 及专业知识后, 在多次工程实践中去锻炼, 在各类设计大 赛中磨炼, 才能达到的。同时, 要求工科学校对学生实践 能力的培养要高度重视, 当作教学主要工作来抓, 才能培 养出适应时代发展的工程技术人才。

\section{参考文献 (References)}

[1] Qiao-hui Pi. How to build the Engineering Students' practical ability training mechanism and the way of realization, Time Education, 2010.
[2] Hao Li, Chang-chong Du. Research and practice of cultivating Engineering Students' ability of innovation and practice. Education practice research, 2010.

[3] Yun-he Pan. Discussion on ability training of engineering students of the Research University. Research in Higher Education of Engineering, 2005.4.

[4] Jun Li, Yong-sheng Dai, Sun Pengyan. Research on the improvement of engineering students' practical ability of science and technology. Petroleum Education, 2004.2. 